\title{
PROSPECTIVE STUDY OF ASSESSMENT OF BODY IRON STORES IN EXCLUSIVELY BREAST-FED INFANTS DURING FIRST SIX MONTHS OF LIFE
}

\author{
Amrita Chauhan ${ }^{1}$, Nirbhay Mehta ${ }^{2}$ \\ ${ }_{13}^{\text {rd }}$ Year Resident, Department of Paediatrics, Mahatma Gandhi Memorial Medical College, Indore, Madhya Pradesh, India. \\ 2Professor, Department of Paediatrics, Mahatma Gandhi Memorial Medical College, Madhya Pradesh, India.
}

\begin{tabular}{l}
\hline ABSTRACT \\
BACKGROUND \\
Intrauterine iron accretion and breast milk are the only sources of iron for full term exclusively breast-fed babies. As the accreted \\
iron stores start depleting, breastfed infants might particularly be at risk of iron deficiency in first few months of life. The objective \\
of the study was to assess the changes in the body iron stores of these exclusively breast-fed infants during their first six months.
\end{tabular}

\section{MATERIALS AND METHODS}

A prospective observational study was conducted in a tertiary care hospital over a period of 1 year. One hundred term healthy babies were enrolled and followed up for first 6 months at pre-decided fixed intervals for their iron status by measuring their haematological parameters (Haemoglobin, Mean Corpuscular Volume and Serum Ferritin). Changes in haematological parameters were measured using paired ' $t$ ' test.

\section{RESULTS}

Of the 100 healthy babies, 52 were evaluated at 4 months and 35 children at 6 months of age because of exclusion from the study due to various reasons. Significant decrease in mean haemoglobin was observed between age group of 2-4 months and 4-6 months. Mean serum ferritin significantly reduced at 6 months in comparison to 2 months and 4 months of age $(p<0.05)$.

\section{CONCLUSION}

Full term exclusively breast-fed babies with normal birth weight were found to have significant decrease in haemoglobin and serum ferritin in the first 6 months of life.

\section{KEY WORDS}

Exclusively Breastfed Infants, Change in Serum Ferritin Level, Body Iron Stores, Mean Corpuscular Volume in Infants

HOW TO CITE THIS ARTICLE: Chauhan A, Mehta N. Prospective study of assessment of body iron stores in exclusively breast-fed infants during first six months of life. J. Evolution Med. Dent. Sci. 2019;8(12):835-838, DOI: 10.14260/jemds/2019/186

\section{BACKGROUND}

Breast milk and intrauterine iron accretion are the major sources of iron for full term babies with normal birth weight without any major illness. With diminished iron levels in mother's milk these babies are at risk for iron deficiency.

According to the World Health Organization recommendation, iron supplementation is to be given after the age of 6 months and till that age the babies should be exclusively breastfed. While the American Academy of Pediatrics recommend the supplementation of $3 \mathrm{mg} / \mathrm{kg} /$ day of iron ferrous sulphate from 4 months of life onwards till 6 months of age in these exclusively breastfed infants.[1]

In our clinical practice in Central India, development of moderate to severe nutritional anemia was seen as early as 68 months of life in infants who were exclusively breastfed, showing that iron stores depletion starts quite earlier than expected.

'Financial or Other Competing Interest': None.

Submission 31-01-2019, Peer Review 06-03-2019,

Acceptance 12-03-2019, Published 25-03-2019.

Corresponding Author:

Dr. Nirbhay Mehta,

Department of Paediatrics,

MGM Medical College,

Indore,

Madhya Pradesh, India

E-mail: drnirbhaymehta@gmail.com

DOI: $10.14260 /$ jemds/2019/186

\section{(c) (1) $(9)$}

Considering the above fact, the present study was undertaken with an objective to assess the changes in iron stores during the first 6 months of life in full term intramural births who were exclusively breastfed till the age of 6 months. Assessment of serum ferritin, haemoglobin and mean corpuscular volume (MCV) was done and evaluation of requirement of iron supplementation was done based on these findings.

\section{MATERIALS AND METHODS}

The study design was Prospective Observational type and was conducted in the Department of Pediatrics, M.G.M. Medical College and Associated Maharaja Yashwant Rao Hospital, Indore and Chacha Nehru Bal Chikitsalaya (CNBC), Indore from May 2017 to April 2018. One hundred full-term infants with birth weight of more than 2500 gms, who will be exclusively breastfed, irrespective of maternal iron supplementation were enrolled at birth. A voluntary written informed consent was obtained from either mother or father of the baby for allowing participation of their infant in the study. These babies were followed-up at 2 months (first visit), 4 months (second visit) and 6 months (third visit) of age. Initially no sample size calculation was done, but we had included one hundred babies during the study period who were voluntarily allowed by their parents to participate in this study. Convenient sampling technique was used for the present study. At every visit, blood samples (2 $\mathrm{ml}$ in EDTA vial and $2 \mathrm{ml}$ in clot activated vial) were collected and sent for analysis. Hemoglobin, serum ferritin and MCV were analysed at each visit. Analysis of haemoglobin level and MCV level was 
done by the Department of Pathology and processed in the Automated Analyzer - Mindray and Sysmex. Blood sample for serum ferritin level was analysed at the Department of Biochemistry using Turbidimetric Latex Immunoassay method, with a special note made whether the mother had taken iron supplementation or not. As our institution is a government run hospital, all the investigations were done free of cost and the parents of the infant were not having any financial implications regarding the participation in the study. Paired ' $\mathrm{t}$ ' test was applied using online statistical software for comparing haemoglobin and MCV level between various follow-ups. Wilcoxon signed rank test was used to compare the serum ferritin values between the various follow ups. A p value of $<0.05$ was considered as statistically significant. Final results were presented in the form of tables and graphs.

Before initiating the study in the institution, clearance from Institutional Ethics Committee was obtained. Also, before including any infant in the study, a voluntary written informed consent was taken from the parents of the infant.

\section{RESULTS}

Of the 100 infants enrolled in the study, 61 were males and 39 were females showing a male preponderance. There was a lost to follow-up of 65 infants by the end of third visit (At 6 months).

Mothers of 66 infants had taken iron supplementation during pregnancy, while the rest 34 did not receive any iron supplementation. The mean serum ferritin level of infants whose mothers had taken iron supplementation was found to be significantly higher $(108.53 \pm 84.33 \mathrm{ng} / \mathrm{dL})$ in comparison to those whose mothers had not received iron supplementation $(69.64 \pm 98.34 \mathrm{ng} / \mathrm{dL})$. The difference was found to be statistically significant $(p=0.042)$. While the haemoglobin and MCV were comparable between the groups of infants ( $p>0.05$ ).

The mean haemoglobin level at second visit was $11.61 \pm$ $1.41 \mathrm{gm} / \mathrm{dL}$, while at third visit it was $10.76 \pm 1.23 \mathrm{gm} / \mathrm{dL}$. There was statistically significant decrease in mean haemoglobin level at third visit $(\mathrm{p}<0.001)$, however, overt anaemia was not observed. [Table 1, Figure 1] Haemoglobin level showed a declining trend over the third visit of life.

The mean MCV at first visit was $80.25 \pm 6.64 \mathrm{fl}$, at second visit it was $80.63 \pm 5.39 \mathrm{fl}$ and at third visit it was $79.95 \pm$ $6.63 \mathrm{fl}$. There was no statistically significant difference seen between any of the visits ( $p>0.05)$, showing a comparable mean MCV at all the visits. [Table 2]

The mean values of serum ferritin at first visit was 106.11 $\pm 119.25 \mathrm{ng} / \mathrm{dL}$, at second visit it was $79.18 \pm 48.98 \mathrm{ng} / \mathrm{dL}$ and at third visit it was $55.73 \pm 28.18 \mathrm{ng} / \mathrm{dL}$, showing a declining trend over third visit of life. On comparison the mean serum ferritin level between first visit and third visit, there was a statistically significant decrease in mean serum ferritin level at third visit $(\mathrm{p}<0.001)$. [Table 3, Figure 2]

\begin{tabular}{|c|c|c|c|}
\hline Visit & No. & Mean \pm SD & p-Value \\
\hline First Visit & 52 & $11.71 \pm 1.59$ & $<0.001^{*}$ \\
\hline Second Visit & 52 & $11.48 \pm 1.46$ & \multirow{2}{*}{$<0.001^{*}$} \\
\hline First Visit & 35 & $11.61 \pm 1.41$ & \multirow{2}{*}{$<0.001^{*}$} \\
\hline Third Visit & 35 & $10.76 \pm 1.23$ & $11.26 \pm 1.45$ \\
\hline Second Visit & 35 & $10.76 \pm 1.23$ & \\
\hline Third Visit & 35 & Table 1. Comparison of Mean Haemoglobin Levels at Different Visits \\
\hline \multicolumn{2}{|c|}{ Paired 't' test applied. ${ }^{*}$ Significant } \\
\hline \multicolumn{2}{r|}{}
\end{tabular}

\begin{tabular}{|c|c|c|c|}
\hline Visit & No. & Mean \pm SD & p-Value \\
\hline First Visit & 52 & $80.25 \pm 6.64$ & \multirow{2}{*}{0.291, NS } \\
\hline Second Visit & 52 & $80.63 \pm 5.39$ & \multirow{2}{*}{0.064, NS } \\
\hline First Visit & 35 & $82.11 \pm 6.40$ & \multirow{2}{*}{0.059, NS } \\
\hline Third Visit & 35 & $79.95 \pm 6.63$ & \\
\hline Second Visit & 35 & $81.67 \pm 5.27$ & \\
\hline Third Visit & 35 & $79.94 \pm 6.63$ & \\
\hline \multicolumn{5}{r}{} \\
\hline \multicolumn{5}{|c|}{ Table 2. Comparison of Mean MCV Levels at Different Visits } \\
\hline
\end{tabular}

\begin{tabular}{|c|c|c|c|}
\hline Visit & No. & Mean \pm SD & p-Value \\
\hline First Visit & 52 & $88.83 \pm 88.30$ & \multirow{2}{*}{0.148, NS } \\
\cline { 1 - 2 } Second Visit & 52 & $75.68 \pm 43.91$ & \multirow{2}{*}{$0.009^{*}$} \\
\hline First Visit & 35 & $106.11 \pm 119.25$ & \multirow{2}{*}{$<0.001^{*}$} \\
\hline Third Visit & 35 & $55.73 \pm 28.18$ & $79.18 \pm 48.98$ \\
\hline Second Visit & 35 & $55.73 \pm 28.18$ & \\
\hline Third Visit & 35 & Table 3. Comparison of Mean Serum Ferritin Levels at Different Visits \\
\hline \multicolumn{4}{|r|}{ Wilcoxon signed rank test applied * Significant. } \\
\hline
\end{tabular}



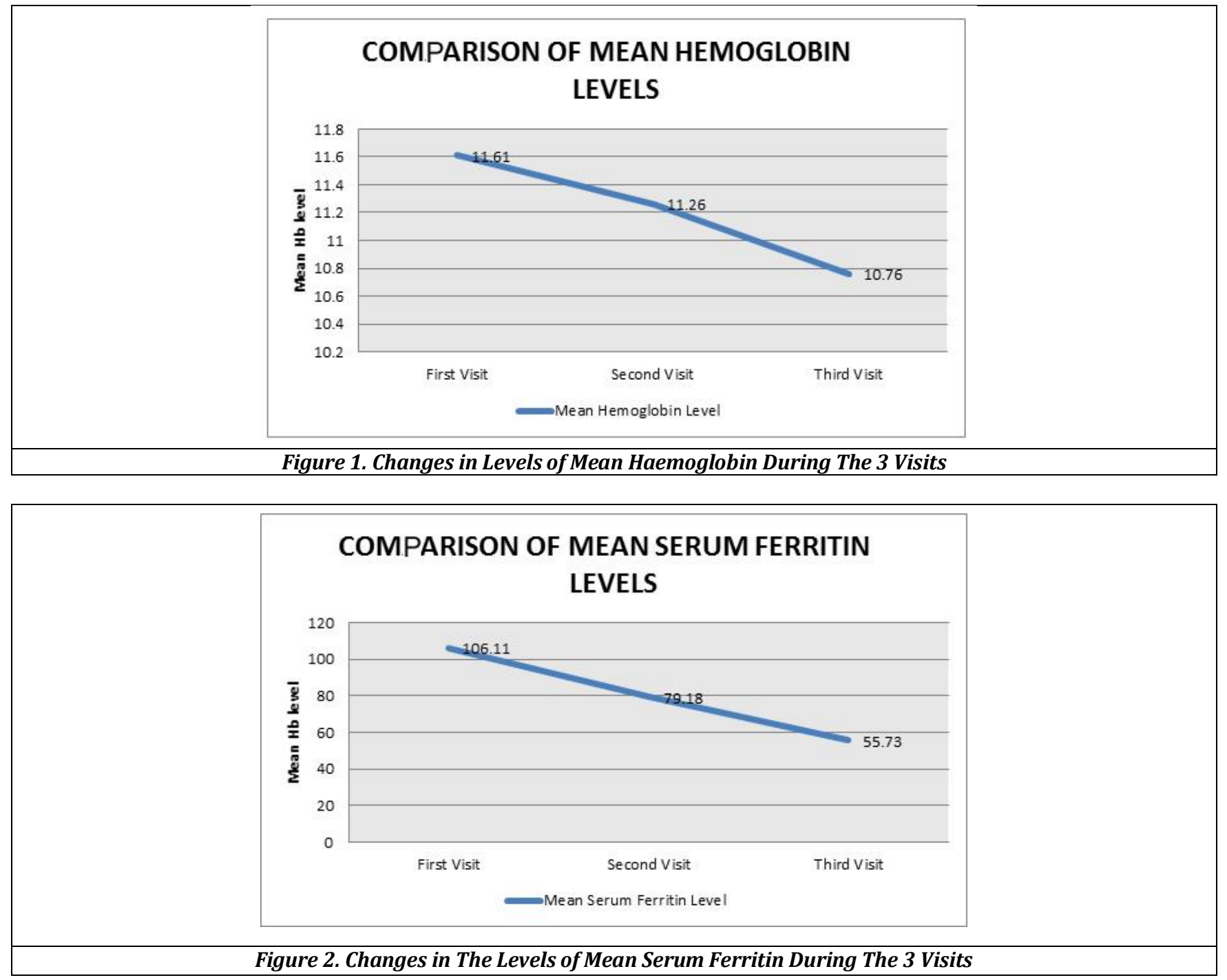

\section{DISCUSSION}

Because of strict inclusion criteria of exclusively breastfed infants, the number of infants enrolled in the study got challenging, thereby restricting the number of participants. The biggest challenge in the present study was collecting 3 blood samples from the healthy children.

Iron supplementation in pregnant women was suggested to improve the iron status of the newborn; however, iron transport to the fetus is an active process and the fetus may be protected from iron deficiency even when the mother has moderate iron deficiency anaemia. Though this fact was supported only by one study done by Preziosi et al (1997),[2] while the study done by Pena-Rosas (2009) ${ }^{[3]}$ reported a lack of convincing evidence that iron supplementation during pregnancy improves infant iron status.

Breastfeeding is an effective preventive measure to counteract iron deficiency-related anaemia as despite low iron concentration in the mother's milk, the bioavailability of iron is high.[1,4] It is a known fact that breastfeeding protects the children from iron deficiency anaemia, but majority of the studies have reported that iron reserves received by the child in the last trimester of pregnancy deplete between 4 and 6 months after birth, even in exclusively breastfed children. $[4,5,6]$

Study done by Krishnaswamy et al (2017) ${ }^{[7]}$ showed a need for iron supplementation at 4 months of life, instead of 6 months as recommended by National Iron Plus Initiative in India.

Qudsia et al (2015) ${ }^{[8]}$ found that healthy breastfed infants do not need any supplementation and fortification of iron and folic acid. They also stated that fortified milk is a better option than cow's milk, which is a poor source of iron and folic acid. This was also supported by Duncan et al (1985).[9]

Marques et al (2014)[10] also stated that exclusive breastfeeding protects infants from iron deficiency anaemia for the first four months of life. After this age, there is an increase in anaemia and iron deficiency rates, which corroborates with the literature.

Kemunto et al (2015)[11] reported that exclusively breastfed infants are at a higher risk of developing iron deficiency anaemia as compared to those introduced to complementary feeds earlier than six months and those given infant formulas alongside breast milk.

\section{CONCLUSION}

Full term, exclusively breast fed babies in our study, showed decrease in haemoglobin and serum ferritin in first 6 months of life. There may be a need for early iron supplementation to these babies to prevent nutritional anaemia. Larger studies involving multiple centres and more cases are required to generate more evidences. Our study showed a positive association between maternal iron supplementation during 
pregnancy and serum ferritin values of exclusively breast fed infants.

We therefore recommend the addition of iron supplementation by the age of 4 months of life in infants who are exclusively breastfed.

\section{ACKNOWLEDGEMENT}

We thank the mothers for allowing their infants to participate in the study and the institutional library to access the journals of importance to support our findings.

\section{Limitation}

The only limitation in our study was number of infants who were included. A larger study with similar variables should be conducted so as to extrapolate the results on the general population.

\section{REFERENCES}

[1] WHO/UNICEF/UNU. Iron deficiency anaemia: assessment, prevention and control, a guide for programme managers. Geneva, World Health Organization, 2001. http://www.who.int/nutrition/publications/micronut rients/anaemia_iron_deficiency/WHO_NHD_01.3/en/i ndex.html. Accessed on 09.03.2017.

[2] Preziosi P, Prual A, Galan P, et al. Effect of iron supplementation on the iron status of pregnant women: consequences for newborns. Am J Clin Nutr 1997;66(5):1178-82.

[3] Peña-Rosas JP, Viteri FE. Effects and safety of preventive oral iron or iron+folic acid supplementation for women during pregnancy. Cochrane Database Syst Rev 2009;(4):CD004736.

[4] Dube K, Schwartz J, Mueller MJ, et al. Iron intake and iron status in breastfed infants during the first year of life. Clin Nutr 2010;29(6):773-8.
[5] World Health Organization. Global strategy for infant and young child feeding. Fifty-Fourth World Health Assembly, provisional agenda item 13.1. WHO. https://apps.who.int/iris/bitstream/handle/10665/4 2590/9241562218.pdf;jsessionid=51EE94194348186 6963C8924A1860F8D?sequence $=1$. Accessed on 25.05.2017.

[6] Friel JK, Aziz K, Andrews WL, et al. A double-masked, randomized control trial of iron supplementation in early infancy in healthy term breast-fed infants. J Pediatr 2003;143(5):582-6.

[7] Krishnaswamy S, Bhattarai D, Bharti B, et al. Iron deficiency and iron deficiency anemia in 3-5 monthsold, breastfed healthy infants. Indian J Pediatr 2017;84(7):505-8.

[8] Qudsia F, Saboor M, Khosa SM, et al. Comparative analysis of serum iron, serum ferritin and red cell folate levels among breast fed, fortified milk and cow's milk fed infants. Pak J Med Sci 2015;31(3):706-9.

[9] Duncan B, Schifman RB, Corrigan JJ Jr, et al. Iron and the exclusively breast-fed infant from birth to six months. J Pediatr Gastroenterol Nutr 1985;4(3):421-5.

[10] Marques RF, Taddei JA, Lopez FA, et al. Breastfeeding exclusively and iron deficiency anemia during the first 6 months of age. Rev Assoc Med Bras (1992) 2014;60(1):18-22.

[11] Kemunto NC. Prevalence of anemia in infants 3-6 months in relation to breastfeeding practices: a case of Mama Lucy Kibaki Hospital, Nairobi-Kenya. Dissertation submitted to the University of Nairobi for the Degree of Masters of Science in Applied Human Nutrition, 2015. 